\title{
市政工程给排水管道施工技术分析
}

\author{
陈士旭 \\ 安徽金鹏建设集团股份有限公司，安徽涂州 239000
}

[摘要]近年来，我国加大了改革开放的力度，从而推动了我国社会经济的飞速发展，在这种形势下城市建设工作得以全面的 推进。在整个市政工程范畴中，给排水管道工程是其中最为重要的一个部分，并且其在城市排水系统中的作用是非常关键的， 其不但与民众的生活息息相关, 并且在推动城市发展方面也具有积极的影响, 所以城市给排水管道施工质量与城市各项功能 的施展存在密切的关联。当下, 城市给排水管道施工工作整体水平并没有达到完善的状态, 其中还存在诸多的问题需要我们 进一步的加以解决, 所以相关工作人员务必要加大力度围绕市政工程给排水管道施工技术展开全面分析研究, 从而切实的对 市政工程给排水管道施工中所存在的问题加以切实的解决, 从根本上确保给排水管道施工质量, 促进社会和谐稳定发展。 [关键词]市政工程; 给排水; 管道施工及技术

DOI：10.33142/ec.v3i6.2098 中图分类号：TU991.05;TU992.05 文献标识码：A

\section{Analysis of Construction Technology of Water supply and Drainage Pipeline in Municipal Engineering}

\author{
CHEN Shixu \\ Anhui Jinpeng Construction Group Co., Ltd., Chuzhou, Anhui, 239000, China
}

\begin{abstract}
In recent years, China has increased the intensity of reform and opening up, thus promoting the rapid development of Chinese social economy. In this situation, urban construction work can be comprehensively promoted. In the whole scope of municipal engineering, water supply and drainage pipeline engineering is one of the most important parts and its role in urban drainage system is very critical, which is not only closely related to people's life, but also has a positive impact on promoting urban development. Therefore, the construction quality of urban water supply and drainage pipeline is closely related to the implementation of various functions of city. At present, the overall level of urban water supply and drainage pipeline construction work has not reached a perfect state. There are still many problems that need to be further solved, so the relevant staff must strengthen the comprehensive analysis and research around the construction technology of municipal engineering water supply and drainage pipeline, so as to effectively solve the problems existing in the construction of municipal engineering water supply and drainage pipeline, fundamentally ensure the quality of water supply and drainage pipeline construction and promote the harmonious and stable development of society.
\end{abstract}

Keywords: municipal engineering; water supply and drainage; pipeline construction and technology

\section{引言}

给排水管道工程在整个城市排水系统中的作用是十分巨大的, 其属于市政工程中最为关键的部分, 并且其与城市 发展以及民众生活存在直接的关联。就现如今城市给排水施工工作实际情况来说, 整体水平较低, 其中存在大量的问 题需要我们进一步的加以切实的解决, 鉴于此, 这篇文章主要针对市政工程给排水管道施工技术展开全面的分析研究, 希望能够对城市建设工作良好发展有所帮助。

\section{1 市政工程给排水管道施工相关概念}

市政工程其实质就是说在整个地区规划建设范围内所建造的为民众提供公共产品以及服务的各类不同性质的建筑 工程。建设主体通常是相关行政机构, 市政工程与民众的生活存在密切的联系, 诸如: 城市道路能够为民众的出行创 造便利。给排水管道工程师市政工程中较为关键的组成部分, 其作用就是输送和调配民众生活以及工业生产用水, 统 一将工业生产所产生的废水进行收集和处理。

\section{2 加强市政工程给排水管道施工技术的意义}

组织开展市政工程建设工作的目的就是为民众创造良好的舒适的生活环境, 提升民众的生活水平, 推动生活和谐 稳定发展。从不同的角度, 利用各种有效的方式方法来促进给排水管道工程施工技术水平的不断提升, 全面切实的将 市政工程给排水管道施工技术加以运用, 及时高效的对给排水管道工程施工过程中所存在的问题给予判断, 利用有效 
的方式方法来加以解决。其次, 提升市政工程给排水管道施工技术整体水平, 可以带动城市给排水管道工程施工质量 的不断提高, 这样才能为城市建设工作的大范围落实给予良好的支持。有效的促进市政工程给排水管道施工技术不断 的完善和优化, 对于从根本上提高工程施工质量能够起到积极的影响作用, 并且可以有效的规避施工质量问题, 增强 管道整体综合性能，所以相关工作人员务必要对市政工程给排水管道施工技术给予重点关注。 ${ }^{[2]}$

\section{3 市政工程给排水管道施工技术存在的问题}

\section{1 施工前期规划不完善}

在正式开展给排水管道施工工作之前, 需要综合各方面实际情况来对排水管道施工工作进行合理的规划, 这样才 能从根本上对给排水管道工程施工质量加以保证, 并且最大限度的规避后续给排水系统在使用过程中出现任何的质量 问题。但是, 在实际实施给排水管道施工工作的时候, 很多的工作人员对于前期规划工作的重要性缺少正确的认识, 这样不但会损害到给排水管道工程的整体施工质量, 并且还会提升给排水工程系统后期使用过程中发生质量问题的概 率, 再加上前期没有对工程所处地区各方面情况进行全面的分析, 所以会导致给排水管道施工计划的可行性较差, 不 但会对民众正常生活造成严重的不良影响，甚至会引发危险事故的发生。

\section{2 管道漏水问题突出}

经过调查分析我们总结出, 市政工程给排水管道工程中最为突出的问题就是管道渗水的问题, 如果给排水管道发 生任何漏水的情况, 那么必然会对工程所处地区的供水和排水系统的运行造成不良影响。在供水系统中, 如果管道发 生漏水的问题, 那么极易引发大范围地区停水的情况。就城市排水系统来说, 排水管道出现漏水的问题, 那么会造成 城市废水以及污水不能高效、顺畅的排放, 并且也会对相关附属排水管道的运行造成一定的限制。如果管道漏水的问 题发生在降雨较多季节的时候, 极易导致城市出现内涝的情况, 最终也会对民众的人身安全形成一定的威胁。引发给 排水管道发生漏水问题的根源有很多, 其中最为重要的根源就是所使用的管道材料不达标以及施工技术水平较差。

\section{3 施工质量管理意识薄弱}

一般情况下, 给排水工程管道施工工作都是由相关行政机构组织开展的, 工程资金都是由政府部门拨款, 工程施 工成本有所保障, 这样对于工程施工效率和施工质量的保证都是非常有帮助的。其次, 给排水工程牵涉到的层面较多, 并且包括大量施工工作, 很多施工单位为了提升工程效率, 所以会选择降低工程施工质量标准, 这样必然会损害到给 排水管道工程的整体质量。其次, 工程质量检测部门在开展各项工作的时候, 因为对工程施工质量管理工作的重要性 缺少正确的认识, 所以没有对给排水管道工程质量进行严格的检验核实, 这样也会引发后期工程使用过程中各类质量 问题的频繁发生。 ${ }^{[3]}$

\section{4 提升市政工程给排水管道施工技术措施}

\section{1 设计图纸全面分析}

在正式组织开展市政给排水管道施工工作之前, 为了能够促进各项施工工作能够按照既定的计划按部就班的进行, 最为重要的就是需要保证工程设计图的合理性, 要想实现上述目的, 就需要在开展给排水管道工程施工工作之前, 组 织专业人员对工程现场各方面情况进行勘查工作, 涉及到: 地质结构、环境情况等等, 并且综合所勘察的各项数据结 果来对工程进行设计。其次, 结合工程实际情况和需求来挑选合适的施工技术, 在进行工程设计的时候, 需要将工程 重点位置在设计图中进行详细的标注, 从而有效的提升后续工程施工的效率和质量, 并且还可以为各项施工工作的实 施给予规范。最后, 在正式开始施工工作之前, 应当安排专业人员对施工过程中可能遇到的各类风险进行预判, 并针 对性的制定有效的预防和解决方案, 保证各项施工工作能够有序的开展。

\section{2 沟槽开挖及支护}

在正式组织开展市政给排水管道工程施工工作之前, 应当切实的制定专门的排水方案, 为沟槽的挖掘工作实施创 造良好的基础。借助人工操作的形式来对地下水位进行合理的控制, 借助集水井的方法来进行排水, 提升管道结构安 设位置的准确性和安全性, 避免管道结构出现腐蚀的问题。施工过程中, 工作人员可以借助降落漏斗来实现对地下水 位的实时监控, 从根本上规避管道出现渗漏的问题。如果发生地下水位高度超标的情况, 施工工作人员可以利用疏通、 节流或者是抽水的方法来对水源进行集中排泄, 增强排水的效果, 为后续各项工作的有序开展创造良好的基础。因为 管道安设之前, 都需要提前挖掘沟槽, 所以管道系统的稳定性通常都与沟槽挖掘的效果存在密切的关联。在实际组织 实施沟槽挖掘施工工作的时候, 需要充分的结合工程设计图来计算沟槽的横断面的大小, 并且充分参考地下水位高度 
情况以及地质结构情况来制定施工方案, 在保证挖掘沟槽达到规定标准的基础上, 还需要对沟槽的规格加以保证, 可 以借助专业挖掘工具和设备来实施挖掘施工工作。要想从根本上对管道安设的效果加以保证, 可以利用支护施工技术 来对沟槽实施处理, 将管道放置在沟槽中, 施工工作人员借助梁柱以及板材结构来进行支撑, 在施工过程中要充分结 合地质结构情况来挑选恰当的支护技术，从根本上对施工安全性加以保证。

\section{3 给排水管线铺设安装}

在完成沟槽挖掘施工工作之后, 要第一时间进行管道线路的安设工作, 首先需要将沟槽内挖掘过程中所产生的各 类杂质进行清理, 为后续管道安设工作的实施创造良好的基础。在进行排水管道安设施工工作的时候, 需要严格按照 样板中心的方位以及设计标高来科学的进行排管。在施工过程中需要将人工操作与机械操作充分的融合起来, 这样才 能促进工程施工效率的提升, 保证各项施工工作能够稳步的实施。不得不说的是, 在利用机械设备进行施工工作的时 候, 需要合理的对机械设备的放置位置进行管控, 尽可能的与沟槽保持良好的距离, 避免沟渠结构出现坡塌的情况。 ${ }^{[4]}$

\section{4 进行闭水试验}

在给排水管道安设施工工作结束之后, 需要针对安装好的排水管道实施闭水试验, 在确保管道系统整体质量的基 础上才能实施回填施工工作, 尽可能的规避管道存在质量问题。闭水试验的要求中明确的指出了, 在实施闭水试验的 管道长度不能小于一千米, 并且需要整个实验系统中需要设置有水井, 将实验涉及到的管道四周利用砖块进行砌筑, 并且要利用一定比例的水泥砂浆对砖块结构表层进行涂抹。在实验结束之后, 针对水井以及管道结构的外部表层结构 情况进行观察, 确保施工质量达到规定标准之后方能实施后续操作。在实施闭水试验的时候, 将实验管道内部充满水, 并且需要保证管道内持续二十四小时充满水, 检查管道是否存在漏水的情况, 在进行管道闭水实验的时候, 要注意尽 可能的避免水源的浪费。

\section{5 沟槽回填环节以及路面恢复}

一般来说, 在项目试验工作完成之后才能实施沟槽的回填施工, 在这个环节中要保证管道两边同时进行回填, 这 样才能确保管道的稳定性。给排水管道施工检核工作结束之后, 在确保检核结果达标之后方能进行后续施工工作, 在 回填施工过程中, 对于土壤中存在的垃圾和杂质要尽可能的进行清除, 在完成回填之后需要对回填土层进行压实处理, 保证在规定的时限内完成回填施工，这样才能确保在既定的时间恢复道路的通畅。 ${ }^{[5]}$

\section{5 结语}

城市给排水管道工程的整体效果不但与城市发展存在关联, 并且与民众的正常生活紧密联系, 所以相关部门以及 工作人员务必要针对给排水管道施工技术进行深入的研究和完善, 推动人类社会和谐稳定发展。

\section{[参考文献]}

[1]朱佳华.市政工程给排水管道施工技术探讨 [J]. 科技创新导报, 2018, 15(35) : 48-50.

[2] 尹景超.市政工程给排水管道施工技术浅谈 [J].江西建材, 2017 (14): 105.

[3] 邬铁梅.浅析市政工程给排水管道施工技术 [J]. 山东工业技术, 2016 (03) : 107.

[4] 曹慧.市政工程给排水管道施工技术研究 [J]. 现代工业经济和信息化, 2016, 6 (01) : 61-62.

[5]卢良龙.浅析市政工程给排水管道施工技术 [J].才智, 2012(23): 40 .

作者简介: 陈士旭 (1986.3-), 男, 毕业院校: 涂州职业技术学院, 道路与桥梁工程技术专业, 职务: 项目经理, 职 称级别: 工程师。 